Michael A. Kuiper

Erwin J. O. Kompanje

\section{Only a very bold man would attempt to define death}

Received: 24 February 2014

Accepted: 27 February 2014

Published online: 25 March 2014

(C) Springer-Verlag Berlin Heidelberg and ESICM 2014

M. A. Kuiper ( $)$

Department of Intensive Care Medicine, Medical Center

Leeuwarden, Leeuwarden, The Netherlands

e-mail:mi.kuiper@wxs.nl

\section{E. J. O. Kompanje}

Department of Intensive Care Medicine, Erasmus MC University Medical Center, Rotterdam, The Netherlands

"The boundaries which divide Life from Death are at best shadowy and vague. Who shall say where the one ends, and where the other begins?"

(Edgar Allan Poe, 1844; The Premature Burial)

"To live is to function. That is all there is in living."

(Oliver Wendell Holmes Jr., 1931)

During history, different criteria to establish death have been used, from putrefaction to brain death. From the eighteenth century through the mid twentieth century, a cardiorespiratory standard of death was used: a person was declared dead when the heart stopped beating and the breathing ceased. Since the beginning of the 1950 s, with the coming of mechanical ventilators, and the ability to manipulate death as a direct consequence of organ support in intensive care departments, the question about what defines the end of human life has become more pressing and more intricate. As the respiration was supported, the circulation could remain, while all signs of function of the brain could have disappeared [1,2]. During the 1960s, criteria were sought to make it possible to recognize those who were beyond hope and consequently could be taken off the ventilator [3]. This eventually led to the Harvard ad hoc committee [4] definition of irreversible coma in 1968. Declaration of death should occur before the respirator is turned off, in order to prevent the stopping of the mechanical ventilation to be the cause of death, but also to make organ donation possible before circulation is stopped $[5,6]$.

Presently we have two windows to look through to death: the circulatory-respiratory window and the neurological window. Although there are two windows (or "two entrances"), but there is just one death ("one exit"). Ultimately the brain has irreversibly stopped functioning, causing the death of the individual. "Individuals die, but their cells continue to metabolize" as Beecher [5], president of the ad hoc committee stated, and who are we to know when the exact moment is that death occurs?

In this issue of Intensive Care Medicine, Shemie et al. [7] publish a forum report on international guideline development for the determination of death, supported by the World Health Organization (WHO) and including an operational definition of human death, being "the permanent loss of capacity for consciousness and loss of all brainstem functions, as a consequence of permanent cessation of circulation or catastrophic brain injury." While, to cite Henry K. Beecher, that only a very bold man would attempt to define death [5], and thus this proposed definition will surely cause criticism, a great merit of the paper is that it aims to steer away from terms that suggest the death of an organ, such as brain death or cardiac death. It also aims to reunite the "two deaths" and return to "one death". Another advantage of the paper is the emphasis that is placed on the clinical evaluation in establishing death.

There are, however, also some problems with the definition. In the context of death determination, "permanent" refers to loss of function that cannot resume spontaneously and will not be restored through intervention [7]. The word "permanent" is used to contrast the 
word "irreversible", permanent referring to a condition that, however long lasting, in theory, could be reversed, and irreversible meaning that function cannot be restored no matter what. This is an important notion: with our present-day technology, many organs can be replaced, or their function supported. Many organs, not all: the brain cannot be replaced. From this we can conclude that the word permanent refers not so much directly to the brain, but merely to the circulation. The circulation could, in many circumstances, be restarted or supported by means of cardiopulmonary resuscitation (CPR) or extracorporeal life support (ECLS). Under circumstances where this would not be desirable (catastrophic brain injury not fulfilling brain death criteria) the word permanent brings about the possibility of choice.

Brain death is not always accepted as death. The story of Jahi McMath, a 13-year-old girl who was declared brain dead after massive blood loss and consequent cardiac arrest after undergoing surgery aimed at relieving symptoms from sleep apnea, and the rejection by her family of the medico-legal finding of death, teaches us that even in countries having laws on brain death, such as the USA, there is opposition to brain death [8]. While the paper by Shemie et al. states that "For the purposes of this forum, death was fundamentally considered a biological event...legal, ethical, cultural and religious perspectives on death were not included," the problem remains that there is still biological function: circulation remains as ventilation is continued and hormonal and other processes can continue. While there is hardly ever any opposition against a declaration of death on circulatory-respiratory standards (we would consider someone who does as mentally incapacitated, and we would strongly object if a family would insist on taking a corpse back home from hospital, claiming that they would continue care privately), there is against brain death. The family of Jahi McMath was allowed to take her from hospital and bring her to an undisclosed facility to continue ventilation and restart enteral feeding [8].
This brings us back to where we started in late 1950s: establishing brain death as a mean to stop treatment in someone who is beyond hope (and beyond harm). This could be an argument against abandoning the dead-donor rule (DDR); the donor needs to be dead before organ donation can occur, and removing of (vital) organs may not cause death. Truog [9] and others have proposed to no longer use the DDR, and accept other alternatives based on the principles of autonomy and nonmaleficence, making organ donation of those who are dying, but not yet dead, possible. There is, however, one major problem with this approach. While establishing death, whether on the basis of neurological or circulatory criteria, in potential organs is problematic; shifting away from the DDR will lead to steering from establishing death to prognosticating death. And while we presently may have philosophical and semantic problems in this regard, prognosticating outcome in those with severe brain injury is much more prone to error [10]. Even if we would doubt the concept of brain death, we need to admit that there is no documented case of a person who regained brain function (or "survived") after a technically correct diagnosis of brain death, fulfilling preconditions and criteria thereof. This would make brain death at least the best predictor of death.

The debate should not center on whether we can define "life" and "death" or not; it should be centered on the question whether current practices of establishing death and organ donation are ethically justifiable.

While the philosophical debate on the definitions of life and death are extremely interesting and needed, we need to be aware of the practical problems the intensive care physician is confronted with. We need operational criteria to guide us in our daily practice, and while the debate on life and death continues, we intensivists make decisions based on the best available guidelines.

Conflicts of interest The authors state that there is no conflict of interest in regard to this paper.

\section{References}

1. Wertheimer P, Jouvet M, Descotes J (1959) À propos du diagnostic de la mort de système nerveux. Dans les comas avec arrêt respiratoire traités par respiration artificielle. La presse Medicale 67:87-88

2. Mollaret P, Goulon M (1959) Le coma dépassé (mémoire préliminaire). Rev Neurol (Paris) 101:3-15

3. Rosoff SD, Schwab RS (1968) The EEG in establishing brain death. A 10 -year report with criteria and legal safeguards in the 50 states.

Electroencephalogr Clin Neurophysiol 24:283-284
4. Ad Hoc Committee of the Harvard Medical School to Examine the Definition of Brain Death (1968) A definition of irreversible coma. Special communication: report of the Ad Hoc Committee of the Harvard Medical School to examine the definition of brain death. JAMA 205:337-340

5. Beecher HK (1970) Definitions of "life" and "death" for medical science and practice. Ann N Y Acad Sci 169:471-474
6. Giacomini M (1997) A change of heart and a change of mind? Technology and the redefinition of death in 1968. Soc Sci Med 44:1465-1482

7. Shemie SD, Hornby L, Baker A, Teitelbaum J, Torrance S, Young K, Capron A, Bernat JL, Noel L, The International Guidelines for Determination of Death Phase 1 Participants, in collaboration with the World Health Organization (2014) International guideline development for the determination of death. Intensive Care Med. doi:10.1007/s00134-0143242-7 
8. Magnus DC, Wilfond BS, Caplan AL (2014) Accepting brain death. N Engl J Med. doi:10.1056/NEJMp1400930
9. Truog RD, Miller FG, Halpern SD (2013) The dead-donor rule and the future of organ donation. N Engl J Med 369:1287-1289
10. Kompanje EJO (2013) Prognostication in neurocritical care: just crystal ball gazing? Neurocrit Care 19:267-268 